\title{
MOVPE of GaSb/InGaAsSb multilayers and fabrication of dual band photodetectors
}

\author{
Yegao Xiao ${ }^{\mathrm{a}}$, Ishwara Bhat ${ }^{\mathrm{a}}$, Tamer F. Refaat ${ }^{\mathrm{b}}$, M. Nurul Abedin ${ }^{\mathrm{c}}$, and Qinghui Shao ${ }^{\mathrm{a}}$ \\ ${ }^{a}$ ECSE Dept, Rensselaer Polytechnic Institute, 110 8th Street, Troy, NY 12180 \\ ${ }^{\mathrm{b}}$ Science and Technology Corporation, NASA Langley Research Center, Hampton, VA 23681 \\ 'Passive Sensor Systems Branch, MS 468, NASA Langley Research Center, Hampton, VA 23681
}

\begin{abstract}
Metalorganic vapor phase epitaxy (MOVPE) of GaSb/InGaAsSb multilayer thin films and fabrication of bias-selectable dual band photodetectors are reported. For the dual band photodetectors the short wavelength detector, or the upper p$\mathrm{GaSb} / \mathrm{n}-\mathrm{GaSb}$ junction photodiode, is placed optically ahead of the long wavelength one, or the lower photodiode. The latter is based on latticed-matched $\mathrm{In}_{0.13} \mathrm{Ga}_{0.87} \mathrm{As}_{0.11} \mathrm{Sb}_{0.89}$ with bandgap near $0.6 \mathrm{eV}$. Specifically, high quality multilayer thin films are grown sequentially from top to bottom as $\mathrm{p}^{+}-\mathrm{GaSb} / \mathrm{p}-\mathrm{GaSb} / \mathrm{n}-\mathrm{GaSb} / \mathrm{n}-\mathrm{InGaAsSb} / \mathrm{p}-\mathrm{InGaAsSb} / \mathrm{p}-\mathrm{GaSb}$ on undoped p-type GaSb substrate, and as n-GaSb/p-GaSb/p-InGaAsSb/n-InGaAsSb/n-GaSb on Te-doped n-type GaSb substrate respectively. The multilayer thin films are characterized by optical microscope, atomic force microscope (AFM), electron microprobe analyses etc. The photodiode mesa steps are patterned by photolithography with wet chemical etching and the front metallization is carried out by e-beam evaporation with $\mathrm{Pd} / \mathrm{Ge} / \mathrm{Au} / \mathrm{Ti} / \mathrm{Au}$ to give ohmic contact on both n- and p-type Sb based layer surfaces. Dark I-V measurements show typical diode behavior for both the upper and lower photodiodes. The photoresponsivity measurements indicate that both the upper and lower photodiodes can sense the infrared illumination corresponding to their cutoff wavelengths respectively, comparable with the simulation results. More work is underway to bring the long wavelength band to the medium infrared wavelength region near $4 \mu \mathrm{m}$.
\end{abstract}

Keywords: GaSb, InGsAsSb, MOVPE, infrared photodiode, dual band photodetector, and optoelectronic devices

\section{INTRODUCTION}

Antimony (Sb) based infrared photodetectors in the mid-infrared (MIR) wavelength range are of great importance because of their wide range of applications for commercial surveillance, atmospheric monitoring, aerospace, military etc. $\mathrm{GaSb}$ substrate is an attractive choice for $\mathrm{Sb}$ based multilayer film growth since the lattice parameters of various $\mathrm{GaSb}$ based ternary and quaternary III-V compound semiconductors can be tailored to match that of GaSb. Their band gaps cover a wide spectral range from $\sim 0.3$ to $1.58 \mathrm{eV}$, or a wavelength range from near-infrared $(0.8 \mu \mathrm{m})$ to $\mathrm{MIR}(4.3 \mu \mathrm{m})$. Various optoelectronic devices such as photodetectors ${ }^{1-3}$, light emitting diodes ${ }^{4,5}$, and laser diodes ${ }^{6,7}$ operating in wavelength range $(1.7-4.4 \mu \mathrm{m})$ have been reported, and particularly photodetectors fabricated from quaternary alloy $\mathrm{Ga}_{\mathrm{x}} \mathrm{In}_{1-\mathrm{x}} \mathrm{As}_{\mathrm{y}} \mathrm{Sb}_{1-\mathrm{y}}$ can provide room temperature operation near the MIR wavelength range ${ }^{3,8}$.

More complex device structures have been reported or proposed recently. Wang et al. ${ }^{9}$ have reported the growth and characterization of InAsSb/GaInAsSb/AlGaAsSb/GaSb heterostructures for wafer-bonded thermophotovoltaic devices. Biefeld et al. ${ }^{10}$ have reported the growth of multi-stage MIR InAsSb emitters. Another kind of device, which involves complex heterostructures, is a multi-color photodetector. Although multi-color infrared detectors can be developed by using classical optical components, or by stacked supperlattice layers ${ }^{11}$, or by type-II interband quantum well structure with nanopillars ${ }^{12}$, the classical approach with optical components is very complicated and not compatible with the recent development of infrared focal plane arrays. The latter two rely heavily on advanced technology to grow supperlattice or stacked supperlattice layers. Especially, the last one involves highly advanced process technology like ebeam lithography to fabricate the photodiodes in small-size pillars with various diameters in order to demonstrate the quantum-size effect. To develop the multi-color, especially, the two-color (or dual band) infrared photodetectors without relying heavily on complex supperlattice growth and advanced process technology, another practical approach is to take the simple stacked arrangement in which the short wavelength detector is placed optically ahead of the long wavelength 
one(s). A good demonstration of such two-color (or dual band) devices would be likely based on Sb based material systems due to the possibility of bandgap tailoring.

In this paper, growth, characterization and fabrication of dual band photodetectors based on GaSb and InGaAsSb epitaxial layers are reported. The metalorganic vapor phase epitaxy (MOVPE) growth of dual band structure and relevant characterization are described in section 2. The device fabrication is presented in section 3 , and the device characterization and analyses are presented in section 4. Finally, a summary is given in section 5.

\section{MOVPE GROWTH AND CHARACTERIZATION}

The growth of multilayer thin films was carried out using in-house built horizontal MOVPE equipment ${ }^{13,14}$. The carrier gas is ultra-pure hydrogen $\left(\mathrm{H}_{2}\right)$ at a flow rate of $4500 \mathrm{sccm}$, and the growth pressure is maintained at 100 Torr with growth temperature stabilized at $600{ }^{\circ} \mathrm{C}$. Organometallic sources include trimethylindium (TMIn, maintained at room temperature), trimethylgallium (TMGa, at $\sim-6{ }^{\circ} \mathrm{C}$ ), tertiarybutylarsine (TBAs, at $\sim-8{ }^{\circ} \mathrm{C}$ ), and trimethylantimony (TMSb, at $\sim 3^{\circ} \mathrm{C}$ ), and the $\mathrm{n}$ - and p-dopant sources are diethyltelluride (DeTe, at room temperature) and silane diluted in ultra-pure $\mathrm{H}_{2}(100 \mathrm{ppm})$, respectively. Dimethylzinc (DMZn) diluted in hydrogen $\left(1100 \mathrm{ppm}\right.$ in $\left.99.9999 \% \mathrm{H}_{2}\right)$ was also used as p-type dopant for certain growths. When growing n-type GaSb and InGaAsSb layers, the DeTe bubbler was operated in an effusion mode with only the bubbler outlet opened. Using this controlling method, n-type doping density is about $8 \times 10^{16} \mathrm{~cm}^{-3}$ for GaSb layer and $10^{18} \mathrm{~cm}^{-3}$ for InGaAsSb layer. This would also avoid the possible contamination of pipelines by the metalorganic DeTe if ultra-pure $\mathrm{H}_{2}$ flow passes through the DeTe bubbler. The growth rate is approximately $3.8-4.0 \mu \mathrm{m} / \mathrm{hr}$ for GaSb and InGaAsSb layers.

Multilayer structures for dual band devices are grown on both p- and n-type GaSb substrates. The schematic layer structures are shown in Fig. 1(a) and (b) for $\mathrm{p} / \mathrm{n} / \mathrm{n} / \mathrm{p}$-on-p and n/p/p/n-on-n photodetectors respectively. It turns out that good quality films could be grown on two types of substrates, $(100) 2^{0} \rightarrow(110)$ and (100) $+6^{0} \rightarrow(111) \mathrm{B}$. With optimized growth parameters, good quality multilayer films could be repeatedly grown. The as-grown multilayer films are characterized and analyzed with optical microscope, atomic force microscope (AFM), X-ray, and electron microprobe etc. The typical alloy concentration for InGaAsSb is $\mathrm{In}_{0.13} \mathrm{Ga}_{0.87} \mathrm{As}_{0.11} \mathrm{Sb}_{0.89}$ as determined by X-ray diffraction and electron microprobe analyses. In Fig. 2, optical microscope image is shown for the surface morphology of the multilayer thin film of an $\mathrm{n} / \mathrm{p} / \mathrm{p} / \mathrm{n}$-on-n structure. The typical cross-hatch pattern observed for the surface morphology of InGaSb epitaxial layer ${ }^{15}$ is almost alleviated here due to the quaternary InGaAsSb layers, which were tailored to match with the lattice structure of GaSb. But due to the multiplicity of the layers and the fluctuation of controlling accuracy on the flow amount and the metal-organic source bubbler temperatures, the surface morphology of such thin films is not as good as that of GaSb layers grown directly on GaSb substrate. Nevertheless, these epitaxial thin films are good enough for device fabrication.

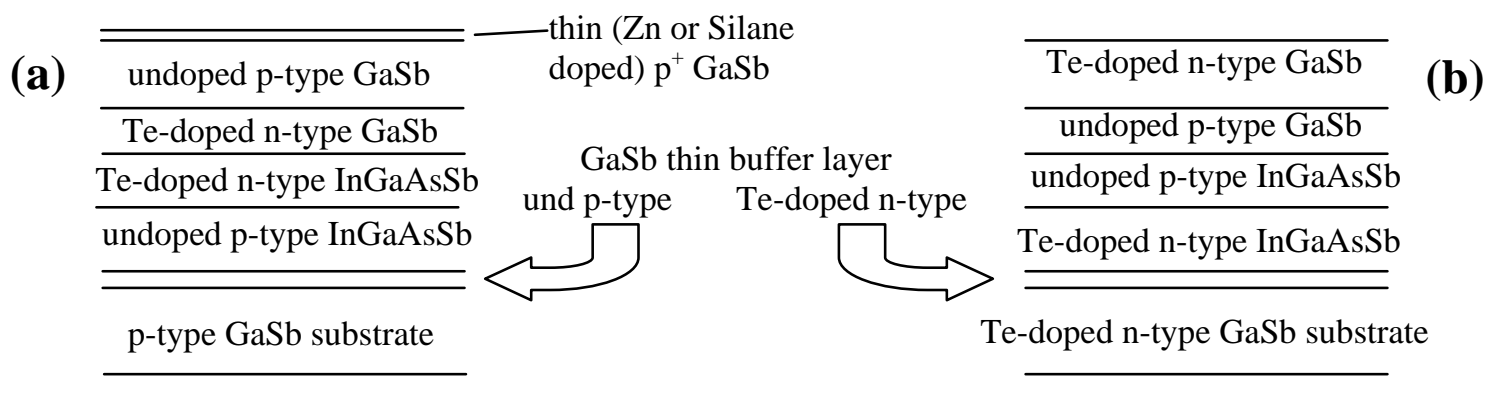

Figure 1: Schematic MOVPE multilayer thin films with p/n/n/p-on-p (a) and n/p/p/n-on-n (b) structures for dual band photodetectors.

The surface morphology of the as-grown dual band multilayer film was also characterized by AFM. Fig. 3 shows the typical AFM scan. The root mean square (RMS) roughness is $4.75 \mathrm{~nm}$. The surface looks rougher than single element diode structures based on GaSb or InGaAsSb layers ${ }^{15}$ due to the multiplicity of layers involving growth of both GaSb and InGaAsSb with possible mismatches not fully eliminated. Nevertheless, these dual band samples with such roughness are acceptable for fabrication and more details will be described in the next section. 


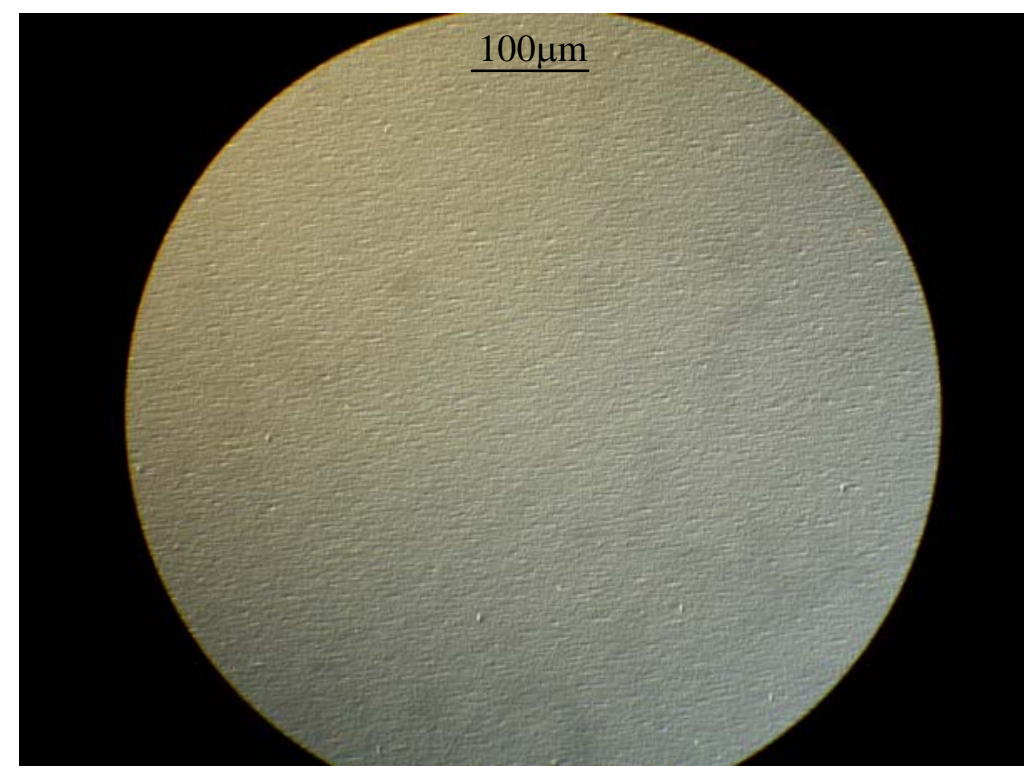

Figure 2: Optical microscope image (20x) of the surface morphology of a multilayer dual-band device with n/p/p/n-on-n structure grown on an n-type (Te-doped) $(100)+6^{0} \rightarrow(111) \mathrm{B}$ GaSb substrate.

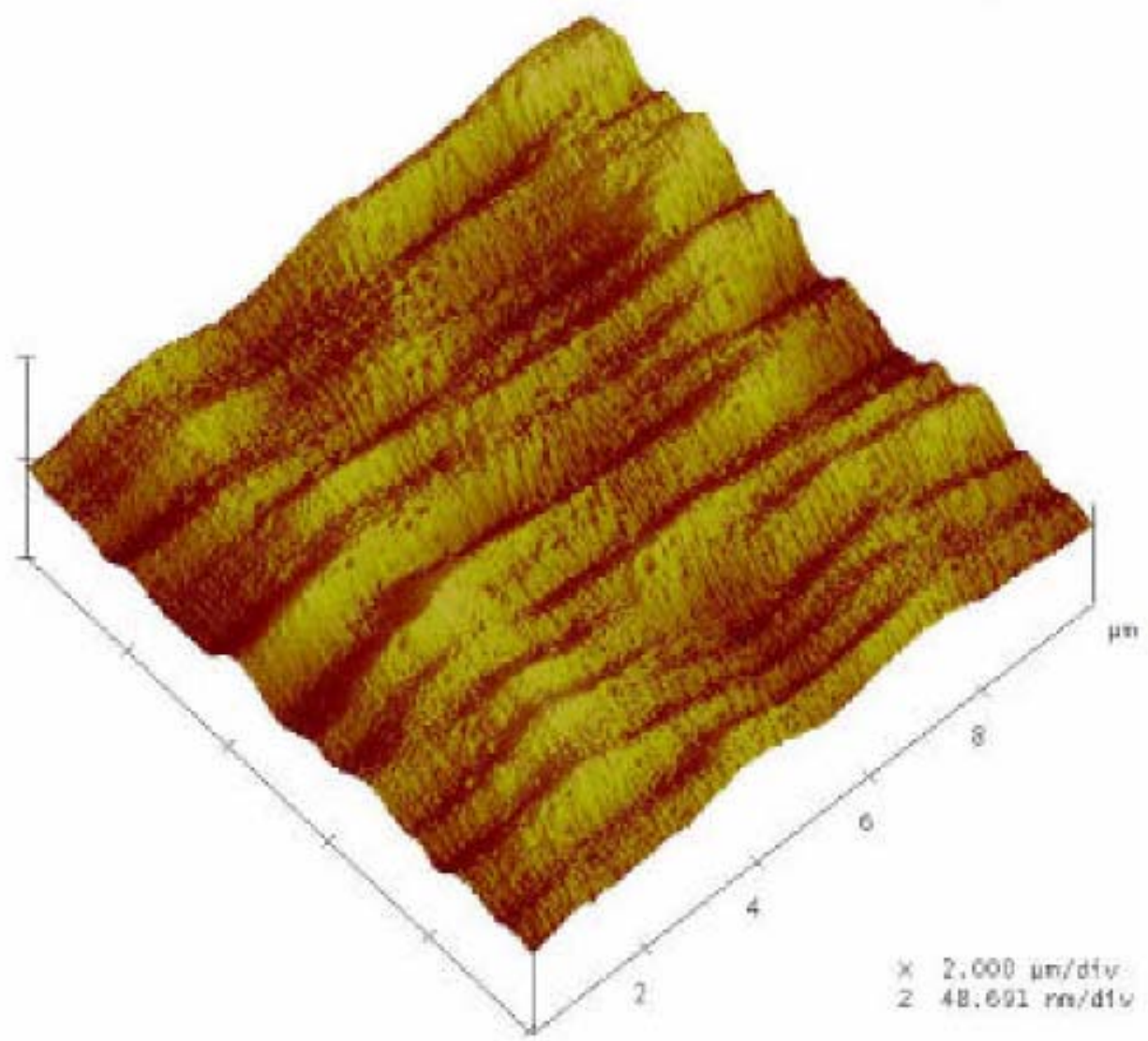

Figure 3: AFM scan of sample shown in Fig. 2. The scanning area is $10 \times 10 \mu \mathrm{m}^{2}$ and the roughness analyses indicate image $\mathrm{Z}$ range about $30 \mathrm{~nm}$ and a RMS roughness about $4.75 \mathrm{~nm}$. The total thickness of multilayer film is about $7.3 \mu \mathrm{m}$. 


\section{DEVICE FABRICATION}

Dual band photodetectors have been fabricated from selected samples with multilayer n/p/p/n-on-n and p/n/n/p-on-p thin films. Without passivation, three mask layers were used to fabricate the upper diode mesa and the lower mesa structures, and to generate liftoff patterns for the front metallization respectively.

Specifically, the selected samples were degreased with hot xylene followed by acetone and methanol rinse (XAM cleaning) at the beginning. Mesas were patterned by using the standard photolithographic technique, and the diode structures were generated with wet chemical etching by using a solution of $\mathrm{HCl}: \mathrm{H}_{2} \mathrm{O}_{2}: \mathrm{NaKTartrate}(33 \mathrm{ml}: 9 \mathrm{ml}: 12 \mathrm{~g}$ in deionized water to form 0.5 liter of solution $)^{16}$. The etching rate for GaSb and InGAsSb are different, and etching rate for $\mathrm{GaSb}$ is somehow slower than that of InGaAsSb. Two mesa steps were etched to form both the upper and lower photodiodes. The first mesa was etched somewhat near the interface between the GaSb and InGaAsSb layers. Spinned photoresist then covered the first-time etched mesa step whereas the lower photodiode mesa structure was etched down to the substrate. Immediately before loading the samples into the e-beam evaporator for front metallization, the samples were immersed in hydrochloric acid $(\mathrm{HCl})$ for about 2 minutes to remove the native oxide layer. For the smallest dual band photodetector, the nominal diameter value for the upper diode is set to $225 \mu \mathrm{m}$ in order to enhance the fabrication yield. By using e-beam evaporation, the metal contacts were evaporated with $\operatorname{Pd}(150 \AA$, first layer $) / \mathrm{Ge}(300 \AA) / \mathrm{Au}(150 \AA) /$ $\mathrm{Ti}(400 \AA) / \mathrm{Au}(1500 \AA$, last layer) on the front, and $\mathrm{Sn} / \mathrm{Au}$ or Ti/Au on the back of n- or p-type substrate respectively. With appropriate layer thicknesses, this $\mathrm{Pd} / \mathrm{Ge} / \mathrm{Au} / \mathrm{Ti} / \mathrm{Au}$ metal configuration could usually provide good ohmic contacts on both $\mathrm{n}$ - and p-type Sb based semiconductor layer surfaces ${ }^{17}$. The schematic device structure for a dual band photodetector and the fabricated device image are shown in Fig. 4(a) and (b) respectively.

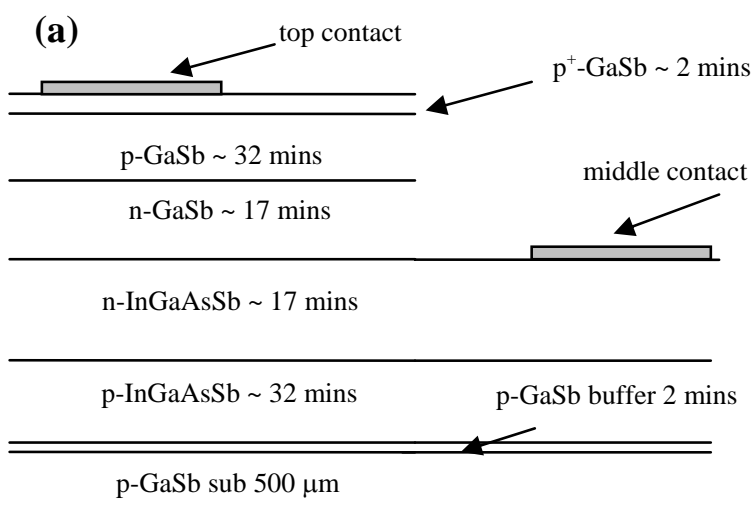

bottom contact

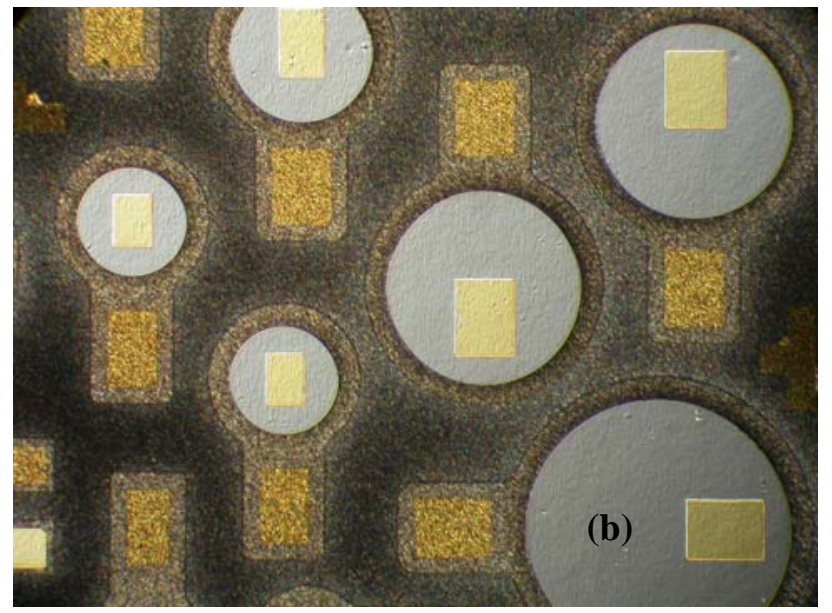

Figure 4: Schematic device structure for a dual band photodetector (p/n/n/p-on-p) (a) and microscope image for the fabricated dual band (n/p/p/n-on-n) photodetector ( 10×) (b).

Whereas good ohmic contact with low contact resistance could be routinely obtained on the front surface of the p-type layers, this has been a problem on n-type layer or material ${ }^{18}$. This is because any annealing of front contact metallization results in increased junction leakage caused by spiking or metal/GaSb reactions. Both $\mathrm{Sn} / \mathrm{Au}$ and $\mathrm{Pd} / \mathrm{Ge} / \mathrm{Au} / \mathrm{Ti} / \mathrm{Au}$ metal configuration have been evaporated as the front contact on n-type Sb based layer. The photodiodes with $\mathrm{Pd} / \mathrm{Ge} / \mathrm{Au} / \mathrm{Ti} / \mathrm{Au}$ metal configuration is more sustainable to annealing than the $\mathrm{Sn} / \mathrm{Au}$ metal configuration if annealing is necessary for good ohmic contact. In general, the photodiodes with $\mathrm{Pd} / \mathrm{Ge} / \mathrm{Au} / \mathrm{Ti} / \mathrm{Au}$ metal configuration show better performance of the I-V curves than the ones with $\mathrm{Sn} / \mathrm{Au}$ metal configuration ${ }^{19}$, and in most of cases, photodiodes with front $\mathrm{Pd} / \mathrm{Ge} / \mathrm{Au} / \mathrm{Ti} / \mathrm{Au}$ metals do not need annealing to achieve ohmic contact. Fig. 5(a) and (b) show the dark I-V curves for un-annealed InGaAsSb photodiodes with front $\mathrm{Sn} / \mathrm{Au}$ and $\mathrm{Pd} / \mathrm{Ge} / \mathrm{Au} / \mathrm{Ti} / \mathrm{Au}$ metal configurations respectively. We can see that the devices with $\mathrm{Sn} / \mathrm{Au}$ are leakier under the reverse bias, and the forward I-V curves show poor contact than devices with $\mathrm{Pd} / \mathrm{Ge} / \mathrm{Au} / \mathrm{Ti} / \mathrm{Au}$. These studies of contact metallization are helpful for fabricating dual band photodetectors with good ohmic contact. 

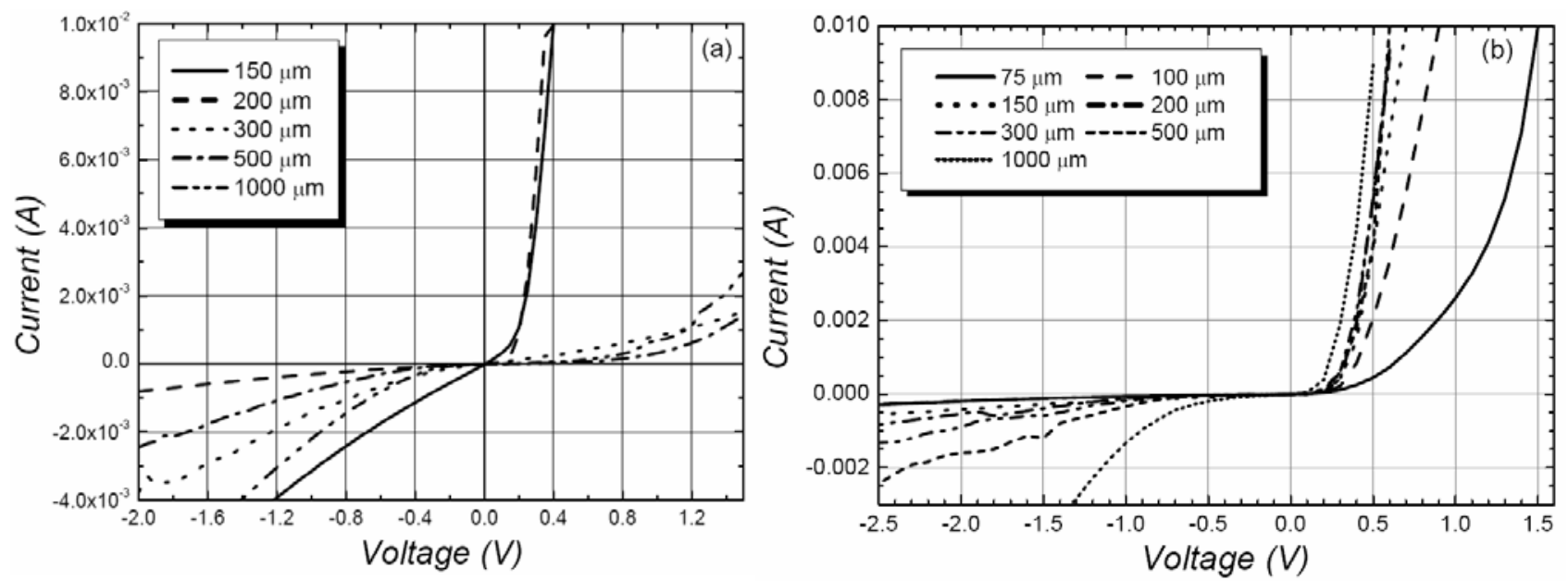

Figure 5: Dark I-V curves for n-on-p-sub InGaAsSb single element photodiodes with Sn/Au (a) and Pd/Ge/Au/Ti/Au (b) front metallization respectively. The curves are shown with various diameter sizes.

\section{DEVICE CHARACTERIZATION AND ANALYSES}

Whereas good ohmic contact is hard to achieve for the front metallization on the top $n-G a S b$ surface for the $n / p / p / n-o n-n$ structure, the fabricated $\mathrm{p} / \mathrm{n} / \mathrm{n} / \mathrm{p}$-on-p dual band photodetector demonstrates diode behavior for both the upper and lower photodiodes with various device sizes. The dark I-V curves are shown in Fig. 6 for a $\mathrm{p} / \mathrm{n} / \mathrm{n} / \mathrm{p}$-on-p dual band photodetector. As seen from Fig. 6, the dark current for both the upper and lower devices show typical exponential dependence on the bias voltage, conforming to the diode theory. The dark I-V curves for five dual band photodetectors with different sizes are also shown in Fig. 7(a) and (b) for the upper and lower photodiodes respectively. The biggest one (1stbig) has a nominal diameter of $775 \mu \mathrm{m}$ for the upper photodiode and $900 \mu \mathrm{m}$ for the lower photodiode. The smallest one (5thbig) has a nominal diameter of $225 \mu \mathrm{m}$ for the upper photodiode and $350 \mu \mathrm{m}$ for the lower photodiode. The contact still needs improvement for some dual band photodetectors as seen from Fig. 7. Annealing these devices at 300 ${ }^{0} \mathrm{C}$ under nitrogen $\left(\mathrm{N}_{2}\right)$ environment for about 20 to 30 seconds usually will result in better ohmic contact. The dark I-V curves in Fig. 7 show that both the upper and lower photodiodes are leaky under reverse bias voltages. This indicates the importance of passivation for these Sb-based devices. Details on some initial passivation work for Sb based photodiodes have been reported elsewhere ${ }^{15}$.

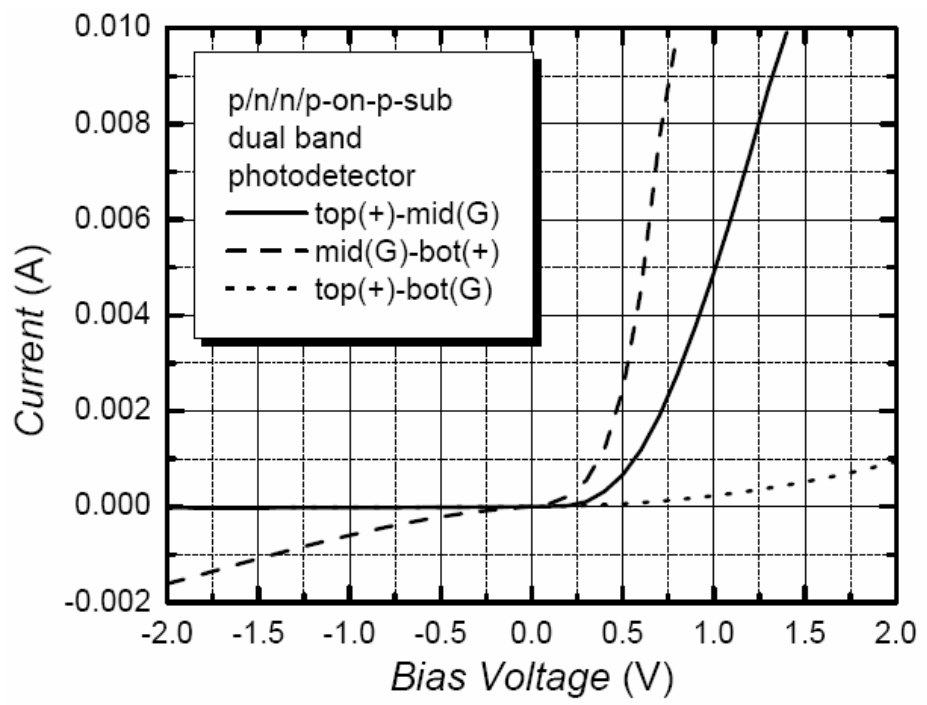

Figure 6: Dark I-V curves for p/n/n/p-on-p dual band photodetector (5thbig). The bias is shown with "+” as the positive contact and "G” as ground. Contacts are labeled as “top", "mid” and "bot”. 

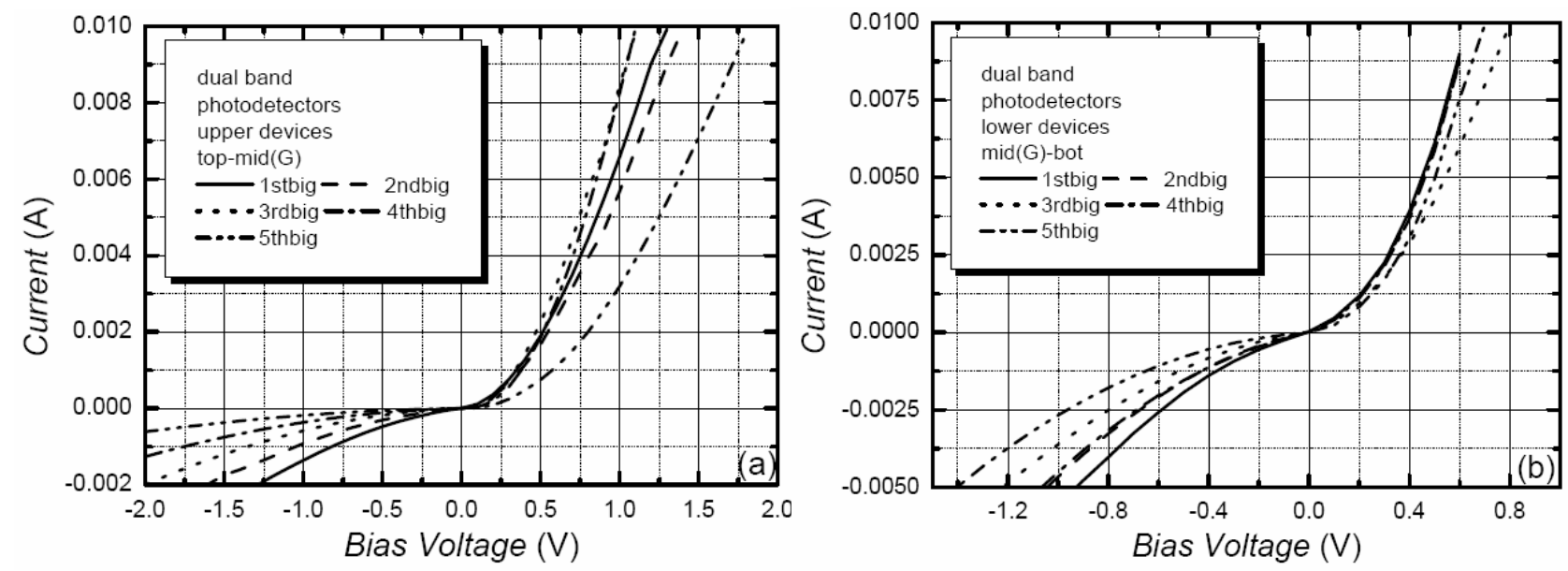

Figure 7: Dark I-V curves of five $\mathrm{p} / \mathrm{n} / \mathrm{n} / \mathrm{p}$ dual band photodetectors with different sizes for upper photodiodes (a) and lower photodiodes (b). The bias with "G" is ground, and contacts are labeled as "top", "mid” and "bot”.

Responsivity profiles for selected dual band photodetectors are also measured within the wavelength range from 1000 $\mathrm{nm}$ to $2200 \mathrm{~nm}$. The output signal of the fabricated photodiode under test is compared with that of a calibrated reference detector $(\mathrm{PbS})$ with the same constant radiation source, and the responsivity of the testing photodiode was evaluated ${ }^{20}$. A $3 \times 3 \mathrm{~mm}^{2} \mathrm{PbS}$ calibrated detector was used as the reference. Spectral resolution of $40 \mathrm{~nm}$ with $0.5 \mathrm{~s}$ and $1.5 \mathrm{~s}$ settling and integration times, respectively, were used to set the $\operatorname{scan}^{21}$. The results are shown in Fig. 8 for a p/n/n/p-on-p device. Both the upper and lower photodiodes can sense the photon illumination up to their cutoff wavelengths ( $\sim 1.7 \mu \mathrm{m} \& \sim 2.0$ $\mu \mathrm{m}$ respectively) limited by their corresponding material bandgaps. Appropriate optimization with the layer thickness design and growth has to be conducted to reduce the photoresponsivity below $1700 \mathrm{~nm}$ for the lower photodiode. In order to achieve photoresponsivity near or above $4 \mu \mathrm{m}$, low bandgap material has to be used for the lower photodiode. Relevant work is currently under way.

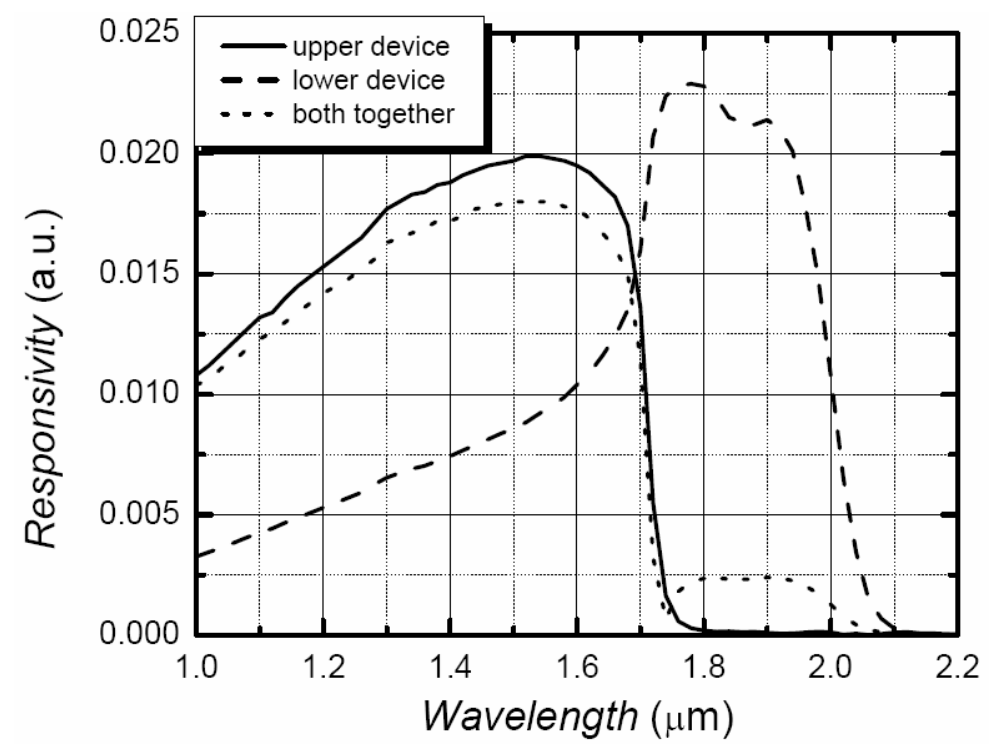

Figure 8: The measured responsivity vs wavelength for one dual band photodetector. Curves shown are for the upper and the lower device, and both devices as a whole. The measurements are conducted at room temperature and zero bias. For both devices as a whole, the photocurrent is collected from the top and bottom contact terminals.

The quantum efficiency profiles for the fabricated dual band photodetector are also simulated with PC1D ${ }^{22}$. All the simulations are done with illumination from top front and the front surface reflection is assumed to be $25 \%$. Carrier recombination is assumed at the top front surface, and at the interfaces between GaSb and InGaAsSb layers. The 
locations for metal contacts are defined according to the actual fabricated device. The relevant results are shown in Fig. 9, where the external quantum efficiency profiles for the upper and lower photodiodes are shown. The cutoff wavelengths for both the upper and the lower photodiodes correspond to their material bandgaps, i.e., GaSb and InGaAsSb respectively. These results are also comparable qualitatively to Fig. 8.

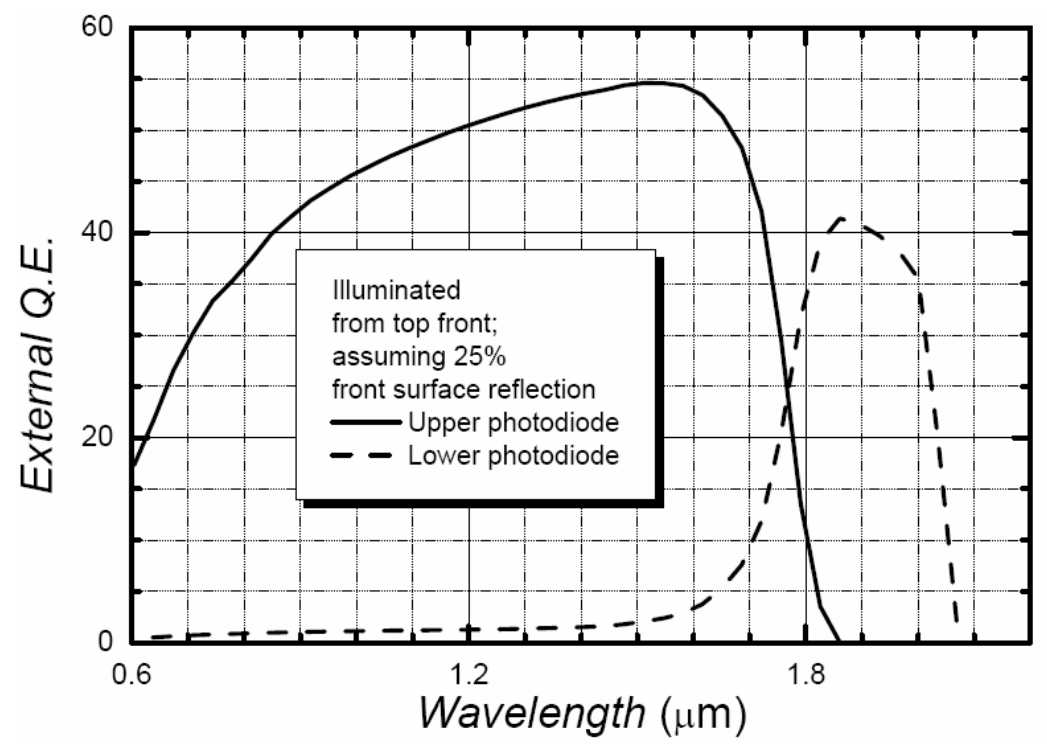

Figure 9: External quantum efficiency profiles simulated by PC1D for the dual band photodetector.

In conclusion, the demonstrated results above indicate that two-color and multi-color photodetectors could be realized by using MOVPE and processing technology which are more conveniently accessible. Since the demonstrated quasi-dual band photodetector is bias-selectable for the upper and lower photodiodes, this indicates its application potential for remote infrared sensing after optimization and relevant array development.

\section{SUMMARY}

In summary, by using MOVPE we have grown GaSb/InGaAsSb dual band multilayer thin films with both p/n/n/p-on-p and $\mathrm{n} / \mathrm{p} / \mathrm{p} / \mathrm{n}$-on-n structures. These multilayer thin films are characterized by optical microscope, AFM, electron microprobe analyses. The dual band photodetectors have been fabricated with two mesa step etching. The mesa steps are patterned by photolithography with wet chemical etching. Dark I-V measurements show typical diode behavior for both the upper and lower photodiodes. The photoresponsivity measurements indicate that both the upper and lower photodiodes can sense the infrared illumination corresponding to their cutoff wavelengths respectively, comparable with the simulation results from PC1D. These demonstrated results indicate that two-color and multi-color photodetectors could be realized by using more commonly available MOVPE and processing technology.

\section{ACKNOWLEDGMENTS}

We like to thank Vinay Bhagwat, Canhua Li, Sunil Rao, Joe Seiler, and Dr. P. Dutta for discussions and useful helps. Thanks are also due to Glenn Farnsworth for his help in obtaining the AFM scans. This work is supported by NASA Langley Research Center under Contract Nos. NAG-1-03040 and NNL04AA67G.

\section{REFERENCES}

1. A. K. Srivastava, J. C. DeWinter, C. Caneau, M. A. Pollack, and J. L. Zyskind, "High performance GaInAsSb/GaSb p-n photodiodes for the 1.8-2.3 $\mu$ m wavelength range,” Appl. Phys. Lett., 48, pp. 903-904, 1986.

2. Y.-M. Sun, J.-M. Wang, and M.-C. Wu, "Liquid-phase epitaxial growth of GaInAsSb and the properties of AlGaSb/GaSb/GaInAsSb separate absorption and multiplication avalanche photodiodes,” Jpn. J. Appl. Phys., 35, pp. 5246-5249, 1996. 
3. O. V. Sulima, M. G. Mauk, Z. A. Shellenbarger, J. A. Cox, J. V. Li, P. E. Sims, S. Datta, and S. B. Rafol, "Uncooled low-voltage AlGaAsSb/InGaAsSb/GaSb avalanche photodiodes,” IEEE Proc. -Optoelectron., 151, pp. 1-5, 2004.

4. N. M. Kolchanova, A. A. Popov, G. A. Sukach, and A. B. Bogoslovskaya, "Thermal-processes in GaInAsSb-based light-emitting-diode (LED) heterostructures,” Semiconductors, 28, pp. 1137-1140, 1994.

5. D. Akhmedov, A. G. Deryagin, S. A. Karandashov, V. I. Kuchinskii, V. M. Smirnov, G. S. Sokolovskii, V. I. Vasil'ev, “GaInAsSb/GaSb double heterostructure light emitting diodes,” Proc. SPIE, 3316, pp. 162-164, 1998.

6. C. Caneau, J. L. Zyskind, J. W. Sulhoff, T. E. Glover, J. Centanni, C. A. Burrus, A. G. Dentai, and M. A. Pollock, “2.2 $\mu \mathrm{m}$ GaInAsSb/AlGaAsSb injection lasers with low threshold current density,” Appl. Phys. Lett., 51, pp. 764766, 1987.

7. T. H. Chiu, J. L. Zyskind, and W. T. Tsang, "Molecular-beam epitaxial-growth of InGaAsSb on (100) GaSb with emission wavelength in the 2 to $2.5 \mu \mathrm{m}$ range,” J. Electron. Mater., 16, pp. 57-61, 1987.

8. C. Caneau, A. K. Srivastava, A. G. Dentai, J. L. Zyskind, and M. A. Pollack, "Room temperature GaInAsSb/ AlGaAsSb DH injection-lasers at $2.2 \mu \mathrm{m}$,” Electron. Lett., 21, pp. 815-817, 1985.

9. C. A. Wang, D. A. Shiau, and D. R. Calawa, "Growth and characterization of InAsSb/GaInAsSb/AlGaAsSb/GaSb heterostructures for wafer-bonded thermophotovoltaic devices,” J. Crystal Growth, 261, pp. 372-378, 2004.

10. R. M. Biefeld, A. A. Allerman, S. R. Kurtz, and K. C. Baucom, "Progress in the growth of mid-infrared InAsSb emitters by metal-organic chemical vapor deposition,” J. Crystal Growth, 195, pp. 356-362, 1998.

11. S.V. Bandara, S. D. Gunapala, J. K. Liu, S. B. Rafol, D. Z. Ting, J. M. Mumolo, R. W. Chuang, T. Q. Trinh, J. H. Liu, K. K. Choi, M. Jhabvala, J. M. Fastenau, W. K. Liu "Four-band Quantum Well Infrared Photodetector Array", Infrared Physics and Technology, 44, pp. 369-375, 2003.

12. A. Gin, Y. Wei, A. Hood, A. Bajowala, Q. Nguyen, V. R. Yazdanpanah, M. Razeghi, G. J. Brown, M. Z. Tidrow, "Nanopillars for Bandgap-Engineering in III-V Optoelectronic Devices,” Proc. SPIE, 5361, pp. 66-75, 2004.

13. H. Ehsani, I. Bhat, C. Hitchcock, R. J. Gutmann, G. Charache, and M. Freeman, "p-type and n-type doping in GaSb and Ga0.8In0.2Sb layers grown by metalorganic vapor phase epitaxy”, J. Crystal Growth, 195, pp. 385-390, 1998.

14. H. Ehsani, I. Bhat, R. J. Gutmann, and G. Charache, "p-type GaSb and $\mathrm{Ga}_{0.8} \mathrm{In}_{0.2} \mathrm{Sb}$ layers grown by metalorganic vapor phase epitaxy using silane as the dopant source”, Appl. Phys. Lett., 69, pp. 3863-3865, 1996.

15. Ishwara Bhat, Yegao Xiao, Vinay Bhagwath, Partha Dutta, Tamer Refaat, and Nurul Abedin, "GaInAsSb-based IR detectors in the $2 \mu \mathrm{m}$ range fabricated from layer structures grown by metalorganic vapor phase epitaxy," oral presentation at the Military Sensing Symposia - MSS, 2005, Charleston, SC, USA, Feb. 14-18, (17 manuscript pages), 2005.

16. C. W. Hitchcock, R. J. Gutmann, H. Ehsani, I. B. Bhat, C. A. Wang, M. J. Freeman, and G. W. Charache, "Tenary and quaternary antimonide devices for thermophotovoltaic applications,” J. Crystal Growth, 195, pp. 363-372, 1998.

17. G. M. Peake, J. G. Cederberg, M. J. Hafich, S. R. Kurtz, R. M. Biefeld, and M. N. Palmasiano, "Common n- and pcontact for serial wiring of quaternary antimonide monolithic interconnected module thermophotovoltaic devices," J. Electrochem. Soc., 149, pp. G416-G419, 2002.

18. M. Shur, Physics of Semiconductor Devices, Prentice-Hall Inc., pp. 210-220, 1990; S. M. Sze, Physics of Semiconductor Devices, 2nd edition, John Wiley \& Sons, pp. 805-807, 1981.

19. C. A. Wang, D. A. Shiau, R. K. Huang, C. T. Harris, and M. K. Connors, "Organometallic vapor phase epitaxy of nGaSb and n-GaInAsSb for low resistance ohmic contacts,” J. Crystal Growth, 261, pp. 379-384, 2004.

20. T. C. Larason, S. S. Bruce, and A. C. Parr, "Spectroradiometric Detector Measurements: Part I-Ultraviolet Detectors and Part II-Visible to Near-Infrared Detectors,” NIST Spec. Publ., Feb. 1998.

21. T. Refaat, N. Abedin, G. Koch, and U. Singh, "InGaAsSb detectors' characterization for 2- $\mu \mathrm{m} \mathrm{CO}_{2}$ lidar/DIAL applications,” NASA Technical Publication, NASA/TP-2003-212140, 2003.

22. PC1D version 5.3, Copyright @ 1998 University of New South Wales. 